


\title{
Cine para los oídos. Un análisis del diseño de sonido de la película Babel
}

\author{
Cinema for the Ears. \\ Analysis of the Sound Design \\ of the Film Babel
}

DOI: https://doi.org/10.22235/d.v0i29.1694

Camilo Pardo Siabato

RESUMEN

Este artículo busca desentramar los procedimientos y estrategias presentes en el diseño de sonido de la película Babel (2006), y su diálogo con los demás componentes cinematográficos, para explorar cómo aportan en la forma propositiva y expresiva cuando el sonido es utilizado en un discurso narrativo. Para ello, se realiza una inmersión en la propuesta sonora de la película mediante la metodología propuesta por Michel Chion en su libro Audiovisión. Este tipo de análisis pone de manifiesto el potencial del sonido como constructor de relato y discurso en los productos audiovisuales, y habilita una percepción más rica de los contextos que aquellos acercamientos que restringen el estudio a una sola mirada.

Palabras clave: diseño de sonido; entes sonoros; audiovisión; cine; Babel; González Iñárritu.

\section{ABSTRACT}

This article seeks to unravel the procedures and strategies in the sound design of the film $\mathrm{Ba}$ bel (2006), and its dialogue with the other cinematographic components, to explore how they contribute in a propositive and expressive way when sound is used in a narrative discourse. To this end, an immersion in the sound proposal of the film is carried out using the methodology proposed by Michel Chion in his bookAudiovisión. This type of analysis highlights the potential of sound as a creator of storytelling and discourse in audiovisual products, and enables a richer perception of contexts than those approaches that restrict study to a single glance. Keywords: sound design; sound entities; audiovisión; cinema; Babel; González Iñárritu.

Camilo Pardo Siabato Universidad beroamericana Ciudad de México, México. ORCID: 0000-00029028-534X cineparalosoidos@gmail.com

Recepción: 25/06/2018 Aceptación: 27/08/2018

Foto: Mercedes Cosco | Archivo Audiovisual Prof. Dina Pintos. Centro Ignis. Universidad Católica del Uruguay. 
1:: Juguete óptico antecesor del espectáculo cinematográfico.

2:: El World Soundscape Project (WSP) fue un grupo educativo y de investigación liderado por Schafer y fundado a fines de los sesenta en la Universidad Simon Fraser de Canadá. Surgió con el propósito de registrar los paisajes sonoros y llamar la atención sobre el impacto de la contaminación acústica (Simon Fraser University, s. f.).

3:: Según Chion, cuando en una película solo se conoce la voz de uno de los personajes (es decir, una voz acusmática) a este personaje se le

llama acusmaser.

4:: Este concepto refiere a que en el cine se favorece la voz por encima de los demás sonidos, tanto en el guion como en el rodaje y la edición. Por eso, para Chion, la voz humana estructura el espacio sonoro que la contiene.
Una introducción a la investigación sonora El cine es un medio de comunicación en el que convergen componentes sonoros y visuales: dos entes fusionados intrínsecamente en todos los productos de esta factura. Sin embargo, este diálogo entre lo que perciben los oídos y los ojos fue establecido mucho antes del nacimiento del cine, antes incluso de que pudieran registrarse técnicamente los sonidos y las imágenes. En una revisión histórica, Jullier (2007, p. 19) apunta que todos los espectáculos de imágenes animadas que se conocen fueron desarrollados con acompañamientos sonoros: desde las marionetas indonesias hasta el praxinoscopio, ${ }^{1}$ siempre hubo música, palabras o sonidos. De esta manera, se puede pensar el entretenimiento como un fenómeno tradicionalmente audiovisual.

No obstante, es importante recordar que hasta hace poco menos de 150 años no se tenía la posibilidad de registrar técnicamente el sonido ni, por ende, de manipularlo, reproducirlo, alterarlo y analizarlo. Fue en 1877 cuando surgió la tecnología capaz de registrar las ondas sonoras: el fonógrafo de Thomas Alva Edison, considerado el primer grabador de sonido (Bejarano, 2007, p. 15). El fonógrafo constaba de un cilindro desplazable con manivela, recubierto con una hoja de estaño, junto con una aguja de acero en su centro, una cortada a bisel para grabar y otra redonda para leer. El alcance de esta tecnología fue un hito histórico para la reflexión alrededor del mundo sonoro, como señala el alemán Marcel Beyer (1999):

El mundo, antes de que pudieran examinarse las voces, no existía. Hasta la invención del fonógrafo por Edison, el mundo de los sonidos solo podía manifestarse exclusivamente en una fugaz presencia, a su lado no existía más que una repetición más queda, más difusa ante el oído interno o, aún menos fiable, la confrontación de sonidos irreales en la imaginación. Luego, en 1877 , de repente la apertura de una esfe- ra insospechada de la acústica... la matización se abrió paso. Desde entonces, cualquier matiz puede servir de referencia para ser comparado arbitrariamente con otro por muy poca diferencia que haya entre ambos (p. 130).

Esta posibilidad tecnológica relativamente reciente propició la investigación moderna de los objetos sonoros y, a partir de ella, se han podido realizar análisis tangibles sobre la naturaleza del sonido, reconocer sus propiedades físicas y la percepción anatómica en los seres humanos, dando como resultado la multiplicación de las posibilidades artísticas y expresivas, tanto en radio como en cine, televisión, música, arte y reflexión sonora.

En las últimas décadas se pueden identificar algunas voces que han llevado adelante investigaciones y que han acuñado conceptos que ayudan a profundizar el estudio del sonido. Una de ellas es la del canadiense Murray Schafer (1977), con sus aportaciones como el concepto de paisaje sonoro y su World Soundscape Project ${ }^{2}$. Otras son las de los franceses Pierre Schaeffer (1967) con sus conceptos de aculogía y música concreta, ésta última plantea la posibilidad de integrar en la música sonidos producidos por otras fuentes distintas a los instrumentos musicales, y Michel Chion (1993), que ha teorizado sobre la interacción entre sonido e imagen y ha aportado una nutrida literatura centrada en el espectro audible con conceptos como audiovisión, acusmaser ${ }^{3}$, vococentrismo ${ }^{4}$, entre otros.

Existe también una variada bibliografía sobre el estudio de la música en general, y en particular respecto a su sinergia con las imágenes en el lenguaje cinematográfico. Tal es el caso de Anahid Kassabian y su Hearing Film: Tracking Identifications in Contemporary Hollywood Film Music (2001), que pone a la música en el centro de la narrativa fílmica o Carol Vernallis (2004) con investigaciones que buscan articular una teoría 
de cómo la música, la letra y la imagen se relacionan entre sí en un producto audiovisual. Y, por supuesto, los trabajos de Michel Chion (1996, 2004) y Theodor W. Adorno (2007) respecto a la música y el cine.

Resulta importante profundizar la discusión académica sobre el papel que desempeña la banda sonora en la cinematografía, entendida como el componente narrativo en el que intervienen todos los elementos audibles (voces, ambientes, música, efectos sonoros, silencios). En este sentido, el presente artículo se propone aportar a las reflexiones sobre el rol del sonido en el lenguaje audiovisual, a partir de un análisis guiado por la metodología presentada por Michel Chion en La audiovisión (1993). El objeto de estudio es la película Babel (2006), dirigida por Alejandro González Iñárritu, cuyo diseño de sonido estuvo a cargo de Martín Hernández.

\section{¿Por qué Babel? El "currículum sonoro"} de González Iñárritu y Hernández

$\mathrm{Al}$ realizar una escucha detallada de algunas de las producciones de González Iñárritu (11'09'01-September 11, Babel y Naran Ja) se percibe el trabajo esmerado que tienen las propuestas sonoras. Podría decirse que el director mexicano no ha sucumbido al autoritarismo de lo visual o, por lo menos, que genera un diálogo más interesante entre lo audible y lo visible que otros cineastas actuales. Es posible que la razón de este cuidadoso manejo de lo sonoro se vincule con sus inicios profesionales en la radio.

Otra enseñanza importante fue la que me dio mi trabajo en el radio. Ahí aprendí a comunicarme con el público. Es un medio muy generoso, profundamente creativo, en donde, literalmente, el único límite es tu capacidad de imaginación (González Iñárritu citado en Pellicer, 2010).

La estadía de González Iñárritu en la producción radial fue de unos cinco años. En sus programas, entretenía a los oyentes durante tres horas diarias con música, relatos de personajes e historias. Esto fungió como una escuela de articulación de ritmo y tono para el futuro director cinematográfico. En la radio también afianzó su relación profesional con el sonidista Martín Hernández, a quien había conocido en las aulas del Departamento de Comunicación de la Universidad Iberoamericana. Su vínculo generó una sinergia de trabajo y reflexión alrededor del universo sonoro que hasta ahora ha tenido como resultado la realización conjunta de ocho producciones multipremiadas: Amores Perros (2000), 11'09'01 - September 11 (2002), 21 Grams (2003), Babel (2006), Biutiful (2010), Naran ja (2012), Birdman (2014) y The Revenant (2015).

Fue en ese período de trabajo radial cuando surgió una pieza publicitaria televisiva (Lobofex, 2006) que podría sintetizar la estructuración mental entre narrativa y sonido del director. El comercial, de WFM Radio, comienza con un rápido recorrido de la cámara en una habitación, mientras unos potentes rayos de luz entran por las ventanas e iluminan su trayectoria. La cámara se detiene frente a una radio antigua, colocada sobre el piso de madera, y enseguida se escucha una voz con textura de transmisión radial: “¿Qué tal? Yo soy Martín Hernández”. Mientras se escucha esta voz, una luz amarilla parpadea sincrónicamente en la pantalla del dial del aparato. A continuación, suena un efecto de cambio de canal de televisión y se ve una breve imagen de ruido blanco. La cámara se mueve hacia la derecha para enfocar otra radio antigua, pero ahora se oye una voz femenina, con el mismo efecto sonoro, que dice: "Yo soy Charo Fernández", seguido de un nuevo corte sonoro y visual. La cámara reencuadra un tercer aparato - un radio más moderno que los anteriores - y hace un recorrido de casi noventa grados sobre este. Una voz masculina, con el mismo efecto de sonido de radio, advierte: "Y yo soy Alejandro González Iñárritu. Estamos un poco nerviosos, hemos sido descubiertos en televisión y nosotros hemos sido siempre gente de radio". 
La realización de este video promocional puede ser tomado casi como un experimento transmediático, ya que presenta la intrusión de un medio sonoro (la radio) en un medio que mezcla imágenes y sonidos (la televisión). Si bien no pretende ni alcanza a considerarse como narrativa transmedia -tal como la propone Scolari (2013)-, este comercial expone un discurso a través de textos irreverentes, contradictorios y sonoros que hablan, entre otras cosas, sobre la construcción del imaginario que tiene el público acerca de los locutores, de las posibilidades de "escuchar por televisión" y "ver por radio"; en suma, pone a dialogar dos medios de comunicación distintos.

Este ejemplo manifiesta la preocupación consciente de González Iñárritu por el diálogo, la tensión, la sinergia y la contraposición que existe, o que potencialmente se puede desarrollar, entre los sonidos y las imágenes que conforman un producto audiovisual. El propio Martín Hernández, en una entrevista con Cristina Alemán durante una reciente edición del Festival de Cine de Morelia, aporta más datos sobre el vínculo de González Iñárritu y el mundo sonoro:

Alejandro es mucho más un ser de sonido que de imagen. Desde luego lo que estoy diciendo es una exageración, pero no es una gran exageración... La narrativa de los sonidos le provoca más detonaciones que la narrativa de la imagen. Pocos directores, si no es que el único con el que yo he trabajado, tienen eso. Hablo del total de la película. Hay directores que sí piden una narrativa sonora con cosas muy específicas... cómo quieren que suene un tren o un personaje en una escena. Pero Alejandro tiene esta detonación sonora en todo el filme (Hernández citado en Alemán, 2015).

Este claro interés por el sonido, su potencial creativo y su expresividad convierten a las producciones de Gon5:: Traducción propia. sobre cinematografía y diseño de sonido. El "curriculum sonoro" con el que cuentan Alejandro González Iñárritu y Martín Hernández reafirma la selección de la película Babel como objeto de estudio, ya que en ella se mezcla el trabajo y la sensibilidad de dos creativos mexicanos para presentar una historia que, en su trama y en su producción, relaciona de diversas maneras diversos aspectos de la comunicación sonora.

\section{Lo que se ha dicho sobre Babel}

Como primer acercamiento a la propuesta sonora que González Iñárritu y Hernández presentan en Babel, se pueden explorar algunos textos que la analizan. Al revisar algunas críticas y reseñas, es claro que el tema que más se comenta es la dificultad de comunicación entre los personajes de la película. Esto puede derivar de la asociación inmediata del título del filme con el mito bíblico. La propuesta sonora de la película recibe pocos comentarios en estos textos, y en su mayoría están centrados en la música (compuesta por el argentino Gustavo Santaolalla) y en algunos ritmos que aparecen en la cinta como los de Celso Piña y su "Cumbia sobre el río", Chavela Vargas con "Tú me acostumbraste" o la música electrónica que se escucha en el bar en Tokio.

Entre las reseñas resalta una de Glenn Kenny (2010), quien da cuenta de lo complejo del proyecto narrativo de González Iñárritu, en cuanto a su forma de tejer el relato y atravesar todos los temas que aborda en el filme.

Babel es una película enormemente ambiciosa. Mientras que cada una de las historias es contada con una factura de intimidad, y la cámara móvil enmarca personajes de manera angosta e incómoda, el arco de la película de estas narrativas conectadas trabaja temas como terrorismo, migración, remanentes del colonialismo y del imperialismo americano y europeo, las multiplicidades a lo largo y ancho del globo (p. 48). ${ }^{5}$ 


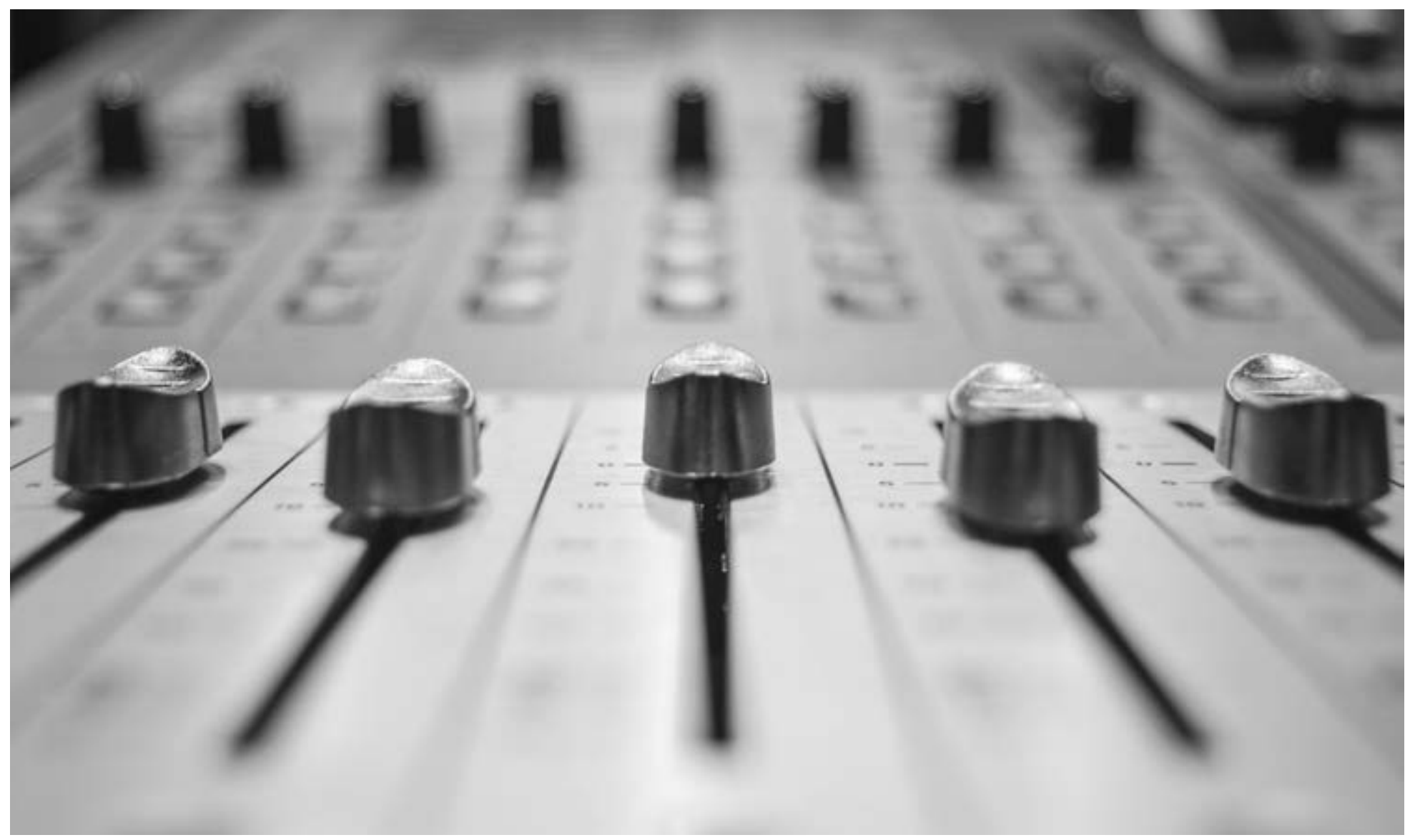

Otros críticos también manejan el término banda sonora para referirse exclusivamente a la música, como en el caso de Fernández Garcés et al. (2013), quienes afırman:

La banda sonora es uno de los elementos que cobra más importancia en el desarrollo del film, convirtiéndose en un actor más en escena. Es multicultural como los personajes, en ella te puedes encontrar un bolero, una cumbia, sonido de banda, así como pop japonés (p. 23).

En muchas películas, al igual que en Babel, los ritmos musicales también pueden ser caracterizados con un mismo personaje que atraviesa las escenas. Sin embargo, dicho personaje estaría construido con una base que deja fuera otras expresiones sonoras. No obstante, como ya se explicó, la música hace parte de los elementos que edifican la banda sonora, y en esta reseña se pueden encontrar elementos que van más allá de los meros ritmos:
La realidad es que para construir la banda sonora se utilizó el mismo instrumento (conexión) en cada una de las tramas: un oud (instrumento de cuerda). Este instrumento carece de trastes, por lo que permite falsear perfectamente el sonido de otros instrumentos. En Asia suena un koto japonés, en América, como una guitarra española y en África, como un barbat (antigua guitarra de origen persa) (Fernández Garcés et al., 2013, p. 24).

Los instrumentos musicales son utilizados para conectar personajes que traspasan los tiempos, los espacios y las culturas de los protagonistas. En este sentido, y pensando en la relación entre sonido y cultura, Pereira Domínguez, Solé Blanch y Valero Iglesias (2012) hablan de una "amalgama" de sonidos preeminentes y definitorios de la variedad, basada en la tradición y en sus diversas evoluciones. Es decir, el sonido se adapta también a la multilateralidad.
Foto: Maicol Rodríguez | Archivo Audiovisual Prof. Dina Pintos.

Centro Ignis. Universidad Católica del Uruguay 
Lo intercultural se acepta como una consecuencia amplia de nuestras innatas distinciones. La película, entonces, plantea un reconocimiento de la otredad a partir de lo sonoro.

Puede percibirse que estos textos dan cierta relevancia al sonido como conector y aglutinador de contextos, aunque se limitan a lo meramente musical o instrumental. Sin embargo, algunos autores reconocen que gracias al personaje de Chieko -la adolescente nipona sorda- la película explora las posibilidades narrativas del silencio de una manera acertada y propositiva. Arroyo (2007), por ejemplo, afirma que la película "capta y transmite emociones sin palabras; las tomas en la discoteca japonesa y la bien lograda ambientación sin sonido invitan al espectador a la reflexión sobre los pensamientos de la joven japonesa”.

Este planteamiento se sintoniza con lo que otros críticos han comentado acerca de la mixtura sonora y musical de la película, complejizada con el uso del silencio. Un análisis de Pellicer (2010) sobre la misma secuencia nocturna en el bar de Tokio comenta:

Chieko [la chica japonesa] vive la soledad de la adolescencia agravada por el aislamiento y la inseguridad que provoca la dificultad para entender lo que dicen los oyentes y la aún mayor dificultad de los oyentes de entender lo que dicen los sordos (p. 119).

Este primer acercamiento a la película a través de las reseñas y críticas es un reflejo de lo que sucede en la literatura sobre lo visual y lo sonoro. Esta última dimensión, estadísticamente, resulta de menor interés, como lo muestra el hecho de que lo poco que se ha escrito sobre la banda sonora se limita a analizar la propuesta musical del filme. Resulta relevante, entonces, indagar con mayor profundidad en todas las dimensiones de la propuesta sonora de Babel, más allá de la música, para explorar de qué manera los distintos entes sonoros colaboran en la construcción del relato.

\section{La metodología de Chion}

En su libro La audiovisión, Michel Chion (1993) plantea una metodología basada en ejercicios puntuales y ejemplificados, en algunos casos, para analizar el vínculo entre sonido e imagen, con otros aspectos inherentes al audiovisual. Se presentan cinco herramientas, que se definen a continuación.

El método de los ocultadores. Consiste en revisar en varias ocasiones una secuencia determinada: algunas veces, con sonido e imagen en simultáneo; otras veces, sin la imagen y, otras, sin el sonido. Así, según Chion, se tiene la posibilidad de oír el sonido tal como es y no como lo transforma la imagen; y ver la imagen tal como es y no como el sonido la recrea. Para esto también es necesario entrenarse en oír y en ver sin prejuicios, sin proyectar las propias percepciones con lo que se sabe de antemano.

Búsqueda de dominancias. Se trata de realizar una taxonomía de la naturaleza de los diferentes elementos sonoros que intervienen en una escena: ¿Hay palabras? ¿Música? ¿Ruidos? ¿Cuál es dominante y se destaca? ¿En qué lugar? Así, se caracteriza el aspecto general del sonido y, en especial, su consistencia. Chion define la consistencia de la banda sonora como la manera en que los diferentes elementos sonoros (ambientes, diálogos, efectos y música) están más o menos incluidos en un mismo flujo, si tienen una misma textura o, por el contrario, se oyen claramente por separado.

Localización de los puntos de sincronización importantes. Con esta herramienta se localizan los eventuales puntos de sincronización destacados, provistos 
de sentido y efecto; vale decir, las conexiones más relevantes entre los sonidos y los demás elementos que forman las secuencias.

Comparación. Muchas veces resulta interesante comparar el sonido y la imagen acerca de una misma cuestión de representación, en sus modos respectivos de situarse en relación con un mismo criterio, que puede aplicarse tanto a uno como a la otra. Por ejemplo, en el plano de la velocidad: el sonido y la imagen pueden tener velocidades contrastadas, y esta diferencia crea una sutil complementariedad de ritmo. Vale decir, se trata de cambiar la banda sonora de un fragmento por otra totalmente distinta y, a partir de eso, encontrar nuevas relaciones y sentidos.

Matrimonio a la fuerza. Lo que propone el autor con esta herramienta es tomar una secuencia de una película, separar la imagen del sonido y unir la banda visual con una selección de sonidos de acompañamiento muy contrastados, pertenecientes a géneros diversos.

Antes de iniciar el proceso de inmersión en una obra audiovisual, Chion (1993) propone rigurosidad en la terminología utilizada:

¿Por qué decir un sonido cuando puede decirse un chisporroteo, un gruñido o un trémolo? El empleo de estas palabras más rigurosas y específicas permite confrontar las percepciones unas con otras y avanzar en su definición y su localización. El simple hecho de tener que buscar en la lengua aquello de lo que ya se dispone crea una actitud de espíritu que incita a interesarse más de cerca por los sonidos (p. 173).

Por ello, no debe sorprender que en los hallazgos y el análisis de este artículo se destaquen algunos conceptos o términos nuevos, con el propósito de relacionarlos con la propuesta sonora de Babel, ya que, de algún modo, estos logran aportar significados y sentidos a la teoría del sonido.

\section{La estructura de Babel}

A partir de del guion de Babel (Arriaga, 2005) se realizó un análisis estructural de la película y se identificaron cuatros líneas narrativas que se repiten de manera cíclica a lo largo de la cinta. Estas líneas se pueden establecer a partir de uno o dos personajes principales, en el siguiente orden:

Yussef. La primera línea argumentativa corresponde a una familia humilde en Marruecos, donde el personaje principal es Yussef, un niño de unos diez años que detona el disparo que desencadena la tragedia principal de la película, cuya acción atraviesa todos los espacios de la narración. A partir del tiro, la familia de Yussef entra en dificultades, pues el padre decide huir de su casa con sus dos hijos varones para no ser capturados. Todo culmina con la muerte de uno de los miembros de la familia en manos de la policía, a causa de una información errada y de la falta de comunicación entre la propia familia, los vecinos y la policía.

Amelia. La segunda línea corresponde a una niñera mexicana, Amelia, y todo su contexto fronterizo entre México y Estados Unidos. Su hijo se casa cerca de Tijuana $\mathrm{y}$, al enterarse que los padres de los niños americanos (Mike y Debbie) que cuida no regresarán pronto a Estados Unidos, decide llevarlos consigo a la fiesta, lo que genera un interesante contraste cultural y sonoro entre los dos países. Sin embargo, al regresar a casa luego de disfrutar de su melódica fiesta, el cruce en la frontera se sale de control y deriva en una cadena de malas decisiones, con un desenlace desesperanzador para ella.

Richard y Susan. La pareja estadounidense que se encuentra de excursión en Marruecos es la protagonista de esta línea narrativa. Ellos son quienes más padecen de incomunicación: aparte de no hablarse entre ellos, debido a una discusión de pareja, se enfrentan a múltiples problemas para lograr dirigirse a los demás en busca de asistencia médica, debido a las diferencias 
Figura 1. Línea argumental de Babel

$$
\begin{aligned}
& \text { Comienzo (tiempo 1) Yussef } \rightarrow \text { Amelia } \rightarrow \text { Richard y Susan } \rightarrow \text { Chieko } \rightarrow \\
& \text { (tiempo 2) Yussef } \rightarrow \text { Amelia } \rightarrow \text { Richard y Susan } \rightarrow \text { Chieko } \rightarrow \\
& \text { (tiempo 3) Yussef } \rightarrow \text { Amelia } \rightarrow \text { Richard y Susan } \rightarrow \text { Chieko } \rightarrow \\
& \text { (tiempo 4) Yussef } \rightarrow \text { Amelia } \rightarrow \text { Richard y Susan } \rightarrow \text { Chieko } \rightarrow \\
& \text { (tiempo 5) Yussef } \rightarrow \text { Amelia } \rightarrow \text { Richard y Susan } \rightarrow \text { Chieko } \rightarrow \\
& \text { (tiempo 6) Yussef } \rightarrow \text { Amelia } \rightarrow \text { Richard y Susan } \rightarrow \text { Chieko. Final }
\end{aligned}
$$

Fuente: Elaboración propia (2018)

idiomáticas y culturales. Se encuentran de vacaciones, no están familiarizados con el idioma árabe que predomina en la región y el guía traductor con el que cuentan no siempre comunica la información correcta.

Chieko. La última línea narrativa corresponde a la adolescente sordomuda Chieko y su padre en Tokio. Ella es una joven con dificultades de comunicación, tanto con su padre como con otros jóvenes. A esta situación se le suma la reciente muerte de su madre y la exploración de la vida sexual que comienza a experimentar. A diferencia de la incomunicación de Richard y Susan, que están en un contexto ajeno, el problema de Chieko es más cotidiano y prolongado por su condición, lo que hace que su personaje sea abordado de una manera sonora particular.

A lo largo de la película, estas cuatro líneas se repiten, en el mismo orden, en seis ocasiones. Este ciclo determina la estructura interna de la película (ver Figura 1) y permite que haya una conexión entre una secuencia y la siguiente de manera única y constante. En otras palabras, existe un ritmo narrativo marcado por cada fragmento de las cuatro historias, que genera una especie de métrica entre las líneas narrativas.

$\mathrm{Al}$ contar las historias escalonadamente y al dosificar 6:: Traducción propia. tiempo y los personajes, se potencia el efecto narrativo cinematográfico del que habla Branigan (1992) cuando conceptualiza que "la luz y el sonido crean los dos sistemas fundamentales de tiempo y espacio, y su interacción causal: sobre la pantalla y como un relato sucesivo. Una de las obligaciones de la narrativa es conciliar esos sistemas”6 (p. 65). En la pantalla, los elementos narrativos de Babel están muy bien comunicados y relacionados entre sí en función de su premisa: la incomunicación. Y aunque esta problemática está planteada en el guion, también está inmersa en los demás elementos que conforman la película.

Para develar las estrategias y herramientas sonoras utilizadas en cada secuencia y en la estructura total de la película, así como su relación con los demás componentes del discurso narrativo, se revisó el guion intercalando una herramienta de la metodología de Chion con otra. Sin embargo, no todas las secuencias fueron revisadas con las cinco metodologías, sino solo algunas de ellas, por razones de tiempo y de producción. De hecho, matrimonio a la fuerza fue el procedimiento menos utilizado en el análisis pues, por su naturaleza, requiere mayores recursos para su realización.

Aplicados los métodos de análisis y realizada la disección de los objetos sonoros en cada una de las 
veinticuatro secuencias en las que se estructura Babel, se revelaron varios aspectos relacionados con el aporte de la banda sonora a la narrativa. Se realizó entonces una selección de los hallazgos más relevantes, o aquellos que pudiesen ser tomados como modelos de estrategias sonoras en cualquier producción audiovisual. A continuación, se presentan estos hallazgos en orden cronológico y agrupados por las conexiones que tienen entre sí.

\section{Los hallazgos: resultados y discusión}

En la primera secuencia, titulada The rifle, el arma se constituye como un objeto mágico, ${ }^{7}$ como lo define Calvino (1989). En este sentido, el sonido refuerza la importancia narrativa del elemento dentro de la trama. El disparo que realiza Yussef a un autobús en movimiento (0:08), desde una colina, es fundamental para el desarrollo de la historia, pues detona la tragedia que atraviesa, de manera directa e indirecta, a todos los personajes. En esa secuencia, cuando Yussef toma el rifle para realizar una prueba de distancia, y antes de que el tiro suene, se genera un precedente a su existencia, a su "deber ser": se propaga un silencio breve en el que los ambientes son percibidos como muy tenues, lo que permite definir claramente el nacimiento del efecto sonoro del disparo.

Barenboim (2008) describe mejor este fenómeno:

El sonido que interrumpe el silencio representa una alteración de una situación existente, mientras que si surge de él es una alteración gradual de la situación existente. En términos filosóficos, podría decirse que es la diferencia entre ser y devenir (p. 19).

Tal vez por ello, en la propuesta sonora de esta secuencia se hace una antesala de silencio, se suprimen los sonidos y se crea una alfombra roja de mutismo ante el efecto sonoro, para que el disparo resuene como un objeto sonoro-mágico.
El sonido final de esta secuencia coincide con el sonido inicial de la siguiente. Los hermanos, tras darse cuenta de que la bala ha pegado en el autobús, corren por la colina y sus pisadas sobre las piedras se mezclan con los pasos de unos niños que corren en una casa, en circunstancias muy diferentes. En este nuevo espacio, el contexto sonoro es distinto al anterior, al igual que la temporalidad, la locación, el país y los personajes.

Otro punto de la película donde se encuentra también este uso del sonido en el montaje es en la secuencia número 11, Local medicine (0:36). En la edición se aprovechan los cortes de los planos para tener efectos distintos de los diálogos, es decir, las voces de los personajes se introducen de un plano a otro y atraviesan los espacios. Además, se escucha dentro de una casa lo que sonoramente sucede afuera: en esa escena se identifica que las voces cambian de acuerdo con el corte y el tamaño del plano.

Por otro lado, en la segunda secuencia, Search for a babysitter, se introduce por primera vez la música en la película y nuevamente el sonido es usado para conectar escenas. En el interior de una casa se comienza a escuchar una música que no se sabe de dónde proviene (0:12). En el siguiente plano, frente a esa casa, se estaciona un automóvil que resulta ser la fuente de dicha música $(0: 13)$. Esta estrategia sonora redunda en que la música inicial de naturaleza extradiegética se transforma en música diegética en la misma escena.

En la secuencia 6, Guilt sick (0:28), se presenta un contraste constante entre el adentro y el afuera; una oposición entre los sonidos interiores de una casa y los exteriores de su ambiente. Y en este continuo diálogo, un efecto de chirrido de puerta se transforma en un estribillo de tensión para los personajes que allí se encuentran.

El recurso de enlazar secuencias con otras a través del sonido es utilizado nuevamente al final de una de las secuencias de Amelia (Crossing the border), pero no solo
7:: Se puede definir el objeto mágico como un signo identificable que hace explicito el nexo entre personas o entre acontecimientos. Por ello, para Calvino, desde el momento en que un objeto aparece en una narración, se carga de una fuerza especial, se convierte en algo como el polo de un campo magnético, un nudo en una red de relaciones invisibles. 
cruzando en sonido de una a otra, sino de una manera más narrativa. En la primera escena (0:34) se presentan niños que corren en una finca intentando atrapar gallinas, con la presencia de sonidos de aleteos, pisadas, risas y gritos de juego que se transmutan, en corte directo, a los sonidos de un grupo de personas en un autobús alrededor de Susan, donde hay gritos, cuerpos rozándose y barullo en varios idiomas (0:36). En este caso, las dos escenas de grupo poseen similitudes sonoras, las texturas se asemejan y hasta parece que tuvieran una misma personalidad. Este tipo de propuesta genera una fluidez en la continuidad sonora y narrativa por demás interesante, que podría ser utilizada en otros proyectos audiovisuales.

En la secuencia denominada In need of a doctor (0:40) aparecen presencias sonoras que no se habían encontrado hasta ahora en la película. En medio de la música emerge un sonido con frecuencias graves, de continuidad sinuosa y con una intensidad que va aumentando de manera constante. Al parecer, este sonido es de naturaleza sintética, es decir, no corresponde a sonidos realizados por instrumentos musicales, sino por sintetizadores o procesadores digitales. Este sonido es cortado por el diálogo telefónico de Richard con su asistente.

En otras escenas también se identifican distintas presencias sonoras que no pueden ser clasificadas dentro de las categorías del sonido en el cine (ambientes, diálogos, efectos y música). Una de las más evidentes se encuentra al inicio de la secuencia Tokyo night (1:08), donde Chieko está, al parecer, en un estado alterado de conciencia después de tomar una píldora que le fue ofrecida por el primo de su amiga. Todos los sonidos propios de la escena son eliminados por completo y reemplazados por un flujo de sonido desconocido, que otra vez no corresponde a una composición musical, sino que se asemeja más a un torrente de distintas entidades sonoras de naturaleza sintética, un caudal 8:: Traducción propia. variables, con tonalidades y texturas diversas que finalmente, a efectos de esta investigación, fueron denominados entes sonoros.

Estas presencias o entes sonoros se encuentran en varias partes de la película: la secuencia 15, No transportation (1:30) comienza precisamente con uno de estos entes y termina con otro distinto; lo mismo ocurre en la secuencia 17, Surrender (1:43), donde se distingue un ente sonoro que desaparece para darle entrada al ambiente que corresponde a la escena próxima. Del mismo modo, en la secuencia 18, Lost in the desert, se detecta un flujo sonoro al comienzo, que apenas se distingue de la música $(1: 46)$.

Por otra parte, al final de la secuencia In need of a doctor, Susan se lamenta de manera desgarradora, pues le están realizando suturas en su herida de bala sin estar anestesiada. Sus gritos contrastan con el comienzo de la escena que le sigue, que es silente y corresponde a la secuencia 8, Police visit (0:45) que, al parecer, pretende emular la experiencia de Chieko en un consultorio odontológico. En una perspectiva subjetiva de ella, que espera ser atendida por el doctor, son eliminados los ambientes, los efectos sonoros y los diálogos, pero se puede ver que la gente está hablando, aunque no se escuche lo que dicen. De hecho, esta escena es la primera sin audio en toda la película, y el silencio será utilizado como estrategia en otras escenas de Chieko.

El final de la trama de Babel se desencadena transcurridas dos horas de la película, a partir de la secuencia 21 (Deported), y de aquí hasta los créditos finales es evidente el privilegio dado a la música. Leaving the village, que corresponde a la secuencia 22, inicia con una pieza musical de Gustavo Santaolalla a base de instrumentos de cuerdas (2:01). En esta propuesta musical se pueden identificar con claridad los narrative cueing, o indicadores narrativos, que conceptualiza Claudia Gorbam (1987): 


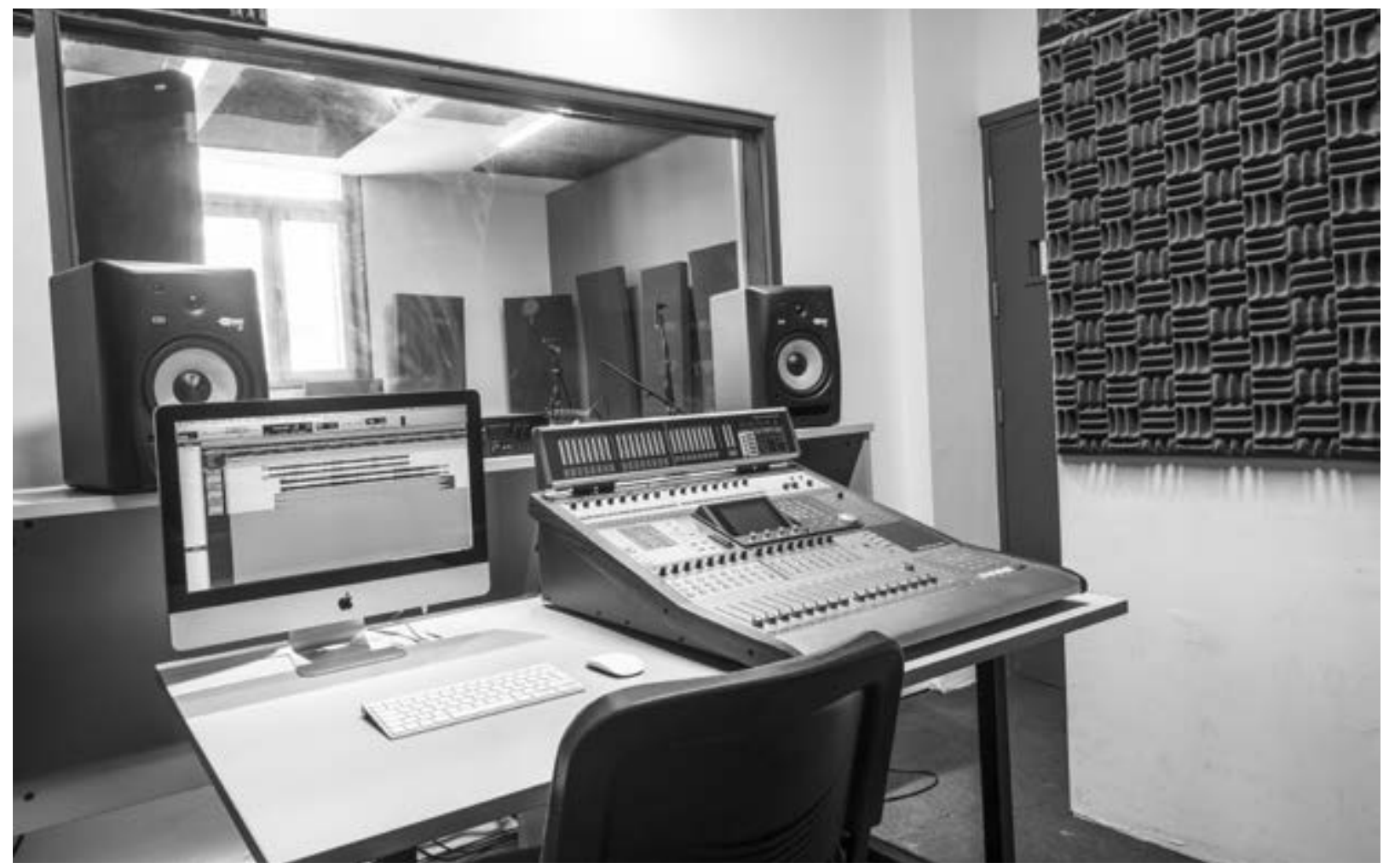

Indicadores narrativos: -referencial/narrativo: la música proporciona claves de referencia y narrativas, por ejemplo, indicando el punto de vista, proporcionando demarcaciones formales y estableciendo escenarios y personajes. La música connotativa "interpreta" e "ilustra" eventos narrativos (p. 73). ${ }^{8}$

Esta melodía es mezclada con los efectos sonoros de un helicóptero y algunas voces y, después de una fuerte presencia melódica, se consigue un breve silencio donde se logran escuchar dos conversaciones que aportan información fundamental para la resolución del argumento: la recuperación de Susan y el ordenamiento cronológico de lo sucedido en la frontera. Todo esto se consigue gracias al sonido y, en este caso, con aportaciones musicales.

En resumen, de las contribuciones sonoras derivadas de la metodología de Chion se reconocen algunos procedimientos utilizados reiteradamente en distintos puntos de la película. Tal es el caso del sonido en sintonía con el montaje o la edición, observable en los cortes entre planos y la continuidad en casi todas las secuencias. Además, sobresale el contraste permanente entre los distintos paisajes sonoros en los que se desarrolla la trama, pues en la construcción de los ambientes se revelan sonoridades constantes sin muchas variaciones morfológicas internas, que sirven para desentonar con otros paisajes.

El uso del silencio también es un punto notable de la propuesta sonora, claramente centralizado en las secuencias de Chieko y enunciando una determinada comunicación con el mundo y con ella misma. Así, es loable el manejo narrativo del sonido en un diálogo constante entre los universos diegéticos y extradiegéticos, pues este contraste, muchas veces difícil de percibir, ayuda a la construcción de un relato de alta expresividad.

En último término, en el diseño de sonido de Babel se detectaron ciertas sonoridades que no se ajustaron a las
Foto: Juan Dogliotti | Archivo Audiovisual Prof. Dina Pintos. Centro Ignis. Universidad Católica del Uruguay 
distintas categorías establecidas, por ello surgió la necesidad de nominar dichas presencias con el concepto de entes sonoros.

Estos entes pueden definirse como aquellos flujos sonoros, dentro de una propuesta cinematográfica, que no tienen un uso aparente o un sentido concreto dentro de la historia y que se distinguen de los ambientes, efectos, diálogos y música. Conceptualmente, un ente sonoro podría ser confundido con un objeto sonoro; sin embargo, este último es considerado como la unidad mínima del sonido, lo que equivale a la gota de un flujo, mientras que el ente es un caudal, un movimiento de sonoridades más elaborado y complejo. También habría que delimitar la diferencia entre ente sonoro y música: si bien acústicamente podrían tener rasgos similares, divergen en cualidades como melodía, armonía y ritmo, que son fundamentales en la música y que los entes sonoros no poseen.

Estas serían las características reconocibles en los entes sonoros:

- $\quad$ Fuente. Elorigendelosentes es desconocido,su naturaleza pertenece a la narración extradiegética.

- $\quad$ Textura. La textura se determina por los materiales que constituyen su naturaleza, es decir, por el ADN sonoro del que están compuestos. En el caso de los entes se utiliza una mezcla de diversos materiales (sonoridades lisas, algunos objetos rugosos, crepitantes, duros y otras formas más), pero siempre se trata de un flujo sonoro peculiar. Vale decir, los entes sonoros cuentan con una nutrida mixtura de morfologías sonoras.

- Duración. A diferencia de los efectos que tienen una vida audible bastante corta, las oscilaciones de los entes sonoros resultan de mayor permanencia. Son presencias que, en algunos casos, atraviesan varias escenas, rompen el tiempo $\mathrm{y}$ el espacio narrativos.

Para finalizar, entonces, resta sumar los entes sonoros a las demás estrategias y procedimientos formales encontrados en Babel -como el uso del sonido en el montaje, el alto contraste entre sonoridades antagónicas o la participación del silencio en algunas secuencias, el diálogo entre los universos diegéticos y extradiegéticos- para hilvanar conceptos que ayuden a enriquecer la forma en que el sonido es utilizado en un discurso narrativo, especialmente en el cinematográfico, de manera propositiva y expresiva.

\section{Resonancias finales: a modo de conclusión}

Luego de los análisis realizados, se puede afirmar que la propuesta sonora de Babel es un flujo complejo que se relaciona y dialoga constantemente con los diferentes elementos de la película: guion, fotografía, actuación y posproducción. En esta película el sonido ha sido diseñado de manera consciente y expresiva por el equipo de realización.

Por un lado, en el montaje, la banda sonora fue aprovechada como elemento de corte o de transición entre un universo narrativo y otro en reiteradas ocasiones, con diversas estrategias (corte, continuidad y contraste). Probablemente, la decisión de usar el sonido como aglutinante de planos y secuencias se deba a su especial fluidez, es decir, a su continuo devenir. En el sonido no es fácil identificar los cambios en sus materiales o matices, lo que permite distraer el sentido del oído y, así, dificultarle al oyente (en este caso, al espectador cinematográfico) la identificación de los cortes de la película. Esta característica no es tan rentable en el trabajo con la imagen, pues cualquier variabilidad o contraste en el plano visual es percibido de inmediato. 
Por otro lado, una de las particularidades de Babel, y que la conecta inexorablemente con el mito bíblico, es la presencia de múltiples acentos dentro de las distintas secuencias, lo que se aprecia en la diversidad de idiomas pronunciados por sus personajes. Claro está que la variedad fonética en los distintos diálogos abona diversos acentos al flujo sonoro y transforma morfológicamente el vococentrismo de Chion (1993), pues este afirma que el sonido en el cine favorece a la voz, destacándola entre los demás sonidos de la banda sonora. Y aunque se puede decir que en Babel no hay un abuso de este vococentrismo, es ineludible reconocer que, como en la mayoría de los guiones cinematográficos, en los diálogos se resuelven muchas de las acciones que desarrollan el relato, y la voz tiene un lugar privilegiado en el diseño sonoro final.

En este sentido, las voces de los personajes fueron trabajadas para que transmitieran algo más allá de la información literal que emitían. Los diálogos de los personajes en Babel adquieren una dimensión más compleja, como sucede en la confesión de Yussef, en la que su voz se destaca por la intencionalidad actoral y por la expresividad que emana del sentimiento con el que habla, aunado a las expresiones corporales, a la reacción de los otros personajes y, finalmente, al montaje. Entonces, la voz es usada como una esencia de los personajes, es la cualidad que define su otredad sonora, la voz más allá de la corporalidad o, en palabras del filósofo Mladen Dolar (2007):

La voz, al ser tan efímera, transitoria, incorpórea y etérea, presenta por ese mismo motivo al cuerpo en su quintaesencia, al tesoro corporal oculto más allá de la envoltura visible, al cuerpo real, único e íntimo, y al mismo tiempo parecería presentar más que el mero cuerpo (p. 87).
En Babel se problematiza el tema de la comunicación $y$, en este sentido, el sonido opera en tres direcciones: la incomunicación por diferencia idiomática, incomprensión y desarraigo; por omisión de las facultades auditivas y por ausencia de información, ya sea por decisión o por falta de interés. Además, el universo sonoro en el que están inmersos los personajes los distingue de los demás. Estos aspectos dejan abierta la discusión acerca de la tragedia de la incomunicación contemporánea, que se hace eco en el mito bíblico de la arrogancia de la naturaleza humana.

Otra presencia muy relevante en la construcción del relato la constituyen los sonidos-detonantes de las acciones de los personajes. Estos aparecen en varias secuencias: un efecto telefónico, un disparo, un efecto de motor alejándose. De una manera poco recurrente en el cine, el sonido desencadena la historia y se convierte en una pieza clave del guion, sin la cual esa parte del relato no sería coherente. Se destaca, entonces, que los objetos sonoros son aprovechados como objetos narrativos desde la misma construcción original del guion.

En contraste a las potencialidades sonoras encontradas en los ambientes, los efectos sonoros, los diálogos, la música y los entes sonoros de Babel, la ausencia de todos ellos también hace parte de la propuesta sonora del filme. El uso del silencio, representado no solo por el personaje sordomudo de Chieko, sino también en el tratamiento de algunos ambientes y escenas específicas en la historia de este personaje, resultan elementos fundamentales para generar contraste y estética sonora en la narrativa. Se identifican aportaciones en el uso del silencio en cuanto este se plantea más allá de la sola ausencia de sonido y se aprovecha la expresividad encontrada en el devenir del sonido siguiente. Esto se aprecia en la ya mencionada secuencia inicial de la película, en la que el primer 
9:: Esta inmersión sonora permite observar el potencial del sonido como constructor de relato y discurso, pues si se revisa con oídos más abiertos la producción de González Iñárritu, tras los hallazgos de esta investigación, se constata que en 11'09"01-September 11 se encuentran entes sonoros que hacen eco en la historia realficcional-biblica, pues la tragedia del desplome de las torres en Nueva York resuena con aquella de la incomunicación en Babel y se sincroniza con la fragmentación idiomática del mito bíblico. Son

flujos sonoros, textuales, reales y ficcionales, que crean sentido para potenciar la premisa del conflicto con la otredad. disparo se genera a partir de un breve silencio. En la propuesta se hace una antesala de silencio para que el disparo resuene como premonición de lo que sucederá. El silencio, entonces, puede ser usado como elemento expresivo, como señala Dolar (2007):

Entonces el arte del silencio es parte de la retórica; es un arte de cómo influir lo mejor posible en el destinatario. Ya los antiguos retóricos proponían agregar un silencio retórico a su bolsa de trucos. El silencio trabaja como el soporte eficaz que inviste las pocas elegidas por su propio peso (p. 181).

El silencio aporta, en la narrativa, por los sonidos que le anteceden pero, sobre todo, por aquellos que nacen después de un vacío sonoro. Babel ejemplifica, de una manera creativa y propositiva, las dificultades en el proceso de comunicación personal, es decir, escala la tragedia que implica la historia bíblica a un nivel cotidiano. Esto se lleva al límite en el tratamiento de algunos personajes, como el caso de Chieko, que es acentuado y particularizado por sus construcciones sonoras y el uso retórico del silencio.

Por otra parte, la funcionalidad dramática de los llamados entes sonoros es una premisa difícil de encontrar en una escucha somera, dada su naturaleza desconocida y polisémica, ya que no se le puede atribuir un sentido único a estos sonidos. Una de las razones de esta dificultad se vincula con el diálogo entre los entes sonoros y su potencial generador de fantasía. Al respecto, Dolar (2007) afirma que "la voz, los ruidos, lo oído, constituyen el núcleo de la formación de la fantasía; una fantasía es una fabulación construida alrededor de un núcleo sonoro" (p. 162). El poder expresivo de los entes sonoros, entonces, se vincula con cada uno de los escuchas, lo que equivale a plantear que la construcción de la fantasía a partir de los materiales propuestos es completado por cada uno de los espectadores, con sus propias vivencias. Los entes sonoros, esos intrusos que nadie invitó y que parecen cargar misteriosamente un sentido en sí mismos, independientemente de lo que se quiera expresar, excederán lo que intenten decir (Dolar, 2007).

En suma, los entes sonoros podrían potenciar la experiencia estética de la película, y esta característica contribuye, de manera contundente, en la expresividad de la banda sonora, que termina por modificar el entramado que resuena en todo Babel. El diseño sonoro de esta película se puede considerar un ejemplo emblemático para desentramar procedimientos, herramientas y estrategias que enmarcan la expresividad sonora y, más aún, le otorgan un sentido estético al sonido en el lenguaje cinematográfico. ${ }^{9}$

Propuestas de sonido como la de Babel permiten argumentar que, en la banda sonora de una película, no solo los sonidos diegéticos son funcionales: la existencia de presencias sonoras casi fantasmagóricas y acusmáticas ayuda a ampliar la expresividad sonora y dejan en el escucha la posibilidad de desafiar sus propias fantasías, como lo plantea Dolar (2007). Los espectadores se transforman, así, en sujetos-escuchas más activos en la experiencia cinematográfica.

\section{Referencias}

Adorno, T. (2007). Composición para el cine. El fiel correpetidor. Madrid, España: Akal.

Alemán, C. (2 de marzo de 2015). ¿Cómo suena el entorno? Entrevista a Martín Hernández. Recuperado de http:// moreliafilmfest.com/como-suena-el-entorno-entrevista-a-martin-hernandez/

Arriaga, G. (2005). Babel. Recuperado de http://www.dailyscript. com/scripts/Babel.pdf 
Arroyo, S. (2007). Quisiera hablar de la película Babel de Alejandro González Iñárritu. Razón y palabra, 55. Recuperado de http://www.razonypalabra.org.mx/cyl/2007/feb1.html

Barenboim, D. (2008). El sonido es vida. El poder de la música. Bogotá, Colombia: Grupo Editorial Norma.

Bejarano, M. (2007). Música concreta. Tiempo destrozado. Bogotá, Colombia: Universidad Nacional de Colombia.

Beyer, M. (1999). El técnico de sonido. Barcelona, España: Débate.

Branigan, E. (1992). Narrative Comprehension and Film. New York, NY: Routledge.

Calvino, I. (1989). Seis propuestas para el próximo milenio. Madrid, España: Ediciones Siruela.

Chion, M. (1993). La audiovisión. Introducción a un análisis conjunto de la imagen y el sonido. Barcelona, España: Paidós.

Chion, M. (1996). El cine y sus oficios. Madrid, España: Cátedra.

Chion, M. (2004). La voz en el cine. Madrid, España: Cátedra.

Dolar, M. (2007). Una voz y nada más. Buenos Aires, Argentina: Bordes Manantial.

Fernández Garcés, V., Martínez Galarza, D., Miedes González, I., Sánchez Torres, J. M., Soler Torro, I., y Soriano Fortanet, L. (2013). Babel: Narrativa de la incomunicación. Recuperado de http://www.bocc.ubi.pt/pag/aavv-2013-02-04.pdf

Gorbam, C. (1987). Unheard Melodies. Narrative Film Music. Bloomington, IN: Indiana University Press.

Jullier, L. (2007). El sonido en el cine. Barcelona, España: Paidós Ibérica.

Kassabian, A. (2001). Hearing Film: Tracking Identifications in Contemporary Hollywood Film Music. Londres, Reino Unido: Routledge.

Kenny, G. (2010). This Can't End Well How We Live Now, or The New Humanism according to Alejandro Gonzalez Iñárritu. Film Society of Lincoln Center, 46(6), 46-49.

Lobofex. (21 de diciembre de 2006). WFM radio [Archivo de video]. Recuperado de https://www.youtube.com/ watch?v=N_m 1 pzmRqKO

Pellicer, J. (2010). Tríptico cinematográfico. El discurso narrativo y su montaje. Ciudad de México, México: Siglo XXI.
Pereira Dominguez, C., Solé Blanch, J., y Valero Iglesias, L. F. (2012). Babel: Cine y comunicación en un mundo globalizado. Polis, 26. Recuperado de http://journals.openedition. org/polis/119

Schafer, M. (1977). The Tuning of the World. Nueva York, NY: Random House.

Schaeffer, P. (1967). El tratado de los objetos musicales. Madrid, España: Editorial Alianza.

Scolari, C. (2013). Narrativas transmedia. Madrid, España: Grupo Planeta.

Simon Fraser University. (s. f.). The World Soundscape Project. Recuperado de https://www.sfu.ca/sonic-studio/WSP/ index.html

Vernallis, C. (2004). Experiencing Music Video. Nueva York, NY: Columbia University Press.

Filmes:

Abounouom, A. (Productor), Arriaga, G. (Escritor), y Iñárritu A. G. (Director). (2006). Babel [Película]. Estados Unidos: Paramount Pictures.

Arriaga, G. (Productor), Arriaga, G. (Escritor), y Iñárritu, A. G. (Director). (2003). 21 Grams [Película]. Estados Unidos: Focus Features.

Arriaga, G. (Productor), Arriaga, G. (Escritor), y Iñárritu, A. G. (Director). 2000). Amores perros [Película]. México: Filmax.

Azcarraga, E. (Productor), Iñárritu, A. G. (Escritor), y Iñárritu, A. G. (Director). (2002). 11'09"01 - September 11 [Película]. Estados Unidos: $\mathrm{ClH}$ Shorts.

Bovaira, F. (Productor), Iñárritu, A. G. (Escritor), y Iñárritu, A. G. (Director). (2010). Biutiful [Película]. México: Mod Producciones.

Iñárritu, A. G. (Escritor \&t Director). (2012). Naran ja [Película]. Estados Unidos: The Amoveo Company.

Iñárritu, A. G. (Productor, Escritor y Director). (2014). Birdman [Película]. Estados Unidos: New Regency Pictures.

Iñáritu, A. G. (Productor, Escritor y Director). (2015). The Revenant [Película]. Estados Unidos: Regency Enterprises. 